\title{
Recent Soft Computing Approaches to User Modeling in Adaptive Hypermedia
}

\author{
E. Frias-Martinez ${ }^{1}$, G. Magoulas ${ }^{2}$, S. Chen ${ }^{1}$, R. Macredie ${ }^{1}$ \\ ${ }^{1}$ Department of Information Systems \& Computing \\ Brunel University \\ Uxbridge, Middlesex, UB8 3PH United Kingdom \\ fenrique.frias-martinez, sherry.chen, robert.macredie\} abrunel.ac.uk \\ ${ }^{2}$ School of Computer Science and Information Systems \\ Birkbeck College, University of London \\ Malet Street, London WC1E 7HX United Kingdom \\ gmagoulasedcs.bbk.ac.uk
}

\begin{abstract}
The ability of an adaptive hypermedia system to create tailored environments depends mainly on the amount and accuracy of information stored in each user model. One of the difficulties that user modeling faces is the necessity of capturing the imprecise nature of human behavior. Soft Computing has the ability to handle and process uncertainty which makes it possible to model and simulate human decision-making. This paper surveys different soft computing techniques that can be used to efficiently and accurately capture user behavior. The paper also presents guidelines that show which techniques should be used according to the task implemented by the application.
\end{abstract}

\section{Introduction}

Adaptive hypermedia (AH) can be defined as the technology that allows personalization for each individual user of a hypermedia application, its content and its presentation according to user preferences and characteristics [29]. The process of personalization of a hypermedia application is implemented through a decision making and personalization engine which adapts the contents according to a user model. In this context it is clear that the key element of an adaptive hypermedia application is the user model. The more information a user model has, the better the content and presentation will be personalized. We consider a user model as a set of information structures designed to represent one or more of the following elements [18]: (1) representation of assumptions about the knowledge, goals, plans preferences, tasks and/or abilities about one or more types of users; (2) representation of relevant common characteristics of users pertaining to specific user subgroups (stereotypes); (3) the classification of a user in one or more of these subgroups; (4) the recording of user behaviour; (5) the formation of assumptions about the user based on the interaction history and/or (6) the generalization of the interaction histories of many users into stereotypes. Fig. 1 presents the architecture of a generic AH system. 


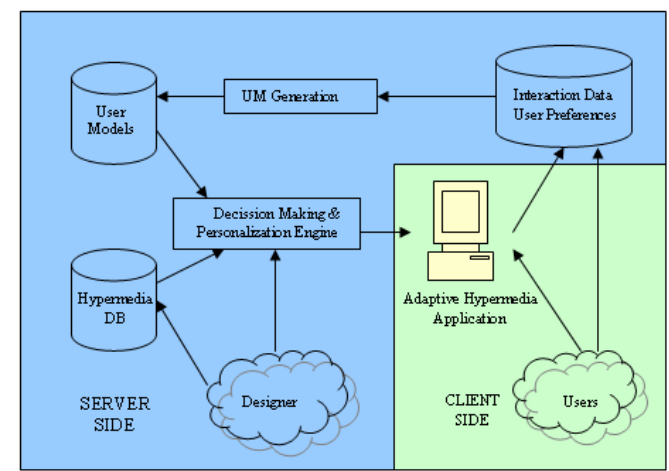

Fig. 1. Generic Architecture of an Adaptive Hypermedia Application.

The architecture of an adaptive hypermedia system is usually divided in two parts: the server side and the client side. The server side generates the user models from a data base containing the interactions of the users with the system and the personal data/preferences that each user has given to the system. These user models, in combination with a hypermedia database, are used by the "Decision Making and Personalization Engine" module to identify user needs, decide on the types of adaptation to be performed and communicate them to an adaptive interface. In this paper, we are going to focus on the "User Model (UM) Generation" module.

A typical user exhibits patterns when accessing a hypermedia system. Machine learning techniques can be applied to recognize regularities in user trails and to integrate them as part of the user model. The limitations of traditional machine learning techniques for modeling human behavior led to the introduction of Soft Computing (SC) for User Modeling (UM). SC technologies provide an approximate solution to an ill-defined problem and can create user models in an environment, such as a hypermedia application, in which users are not willing to give feedback on their actions and/or designers are not able to fully define all possible interactions. Human interaction is a key component of any hypermedia application, which implies that the data available will be usually imprecise, incomplete and heterogeneous. In this context SC seems to be the appropriate paradigm to handle the uncertainty and fuzziness of the information available to create user models [28]. The elements that a user model captures (goals, plans, preferences, common characteristics of users) can exploit the ability of SC of mixing different behaviors and capturing human decision processes in order to implement a system that is more flexible and sensible in relation to user interests. Different techniques provide different capabilities. For example, Fuzzy Logic provides a mechanism to mimic human decision-making that can be used to infer goals and plans; Neural Networks a flexible mechanism for the representation of common characteristics of a user and the definition of complex stereotypes; Fuzzy Clustering a mechanism in which a user can be part of more than one stereotype at the same time and NeuroFuzzy systems a mechanism to capture and tune expert knowledge which can be used to obtain assumptions about the user.

This paper presents a survey of different SC techniques available for modeling user behavior. The paper's intentions are (1) to give a perspective to the $\mathrm{AH}$ community 
about the potential of applying SC techniques to UM and (2) to give basic guidelines about which techniques can be useful for a given adaptive application.

\section{A Taxonomy of Soft Computing-based User Models}

User models can be classified according to two main elements: (1) the granularity of the model, a model can be created for each individual user (content-based modeling) or for clusters of users (collaborative modeling); and (2) the type of task for which the model is going to be used. We have defined four basic types of tasks: (i) Prediction (P), (ii) Recommendation (R), (iii) Classification (C) and (iv) Filtering (F). Prediction is the capability of anticipating user needs using past user behavior. A basic assumption is made with this approach: a user's immediate future is very similar to his/her immediate past. In the literature this is traditionally presented as content-based filtering. Recommendation is the capability of suggesting interesting elements to a user based on some extra information; for example from the items to be recommended or from the behavior of other users. In this context, recommendation is what in the literature is known as collaborative filtering. Classification builds a model that maps or classifies data items into one of several predefined classes. Filtering is defined as the selection of a subset of items that are interesting to a user from the original set of items. In general, any of the previous tasks can be implemented using knowledge stored in the different user model elements described in Section 1. For example, a filtering task can be implemented using knowledge stored in user preferences, or by classifying the user in a stereotype (or in more than one stereotypes). A prediction task can be implemented using the knowledge captured by the user's goals but also by the classification of the user in a stereotype, etc. In the following subsections we present a number of SC techniques and give examples of $\mathrm{AH}$ applications that employ the particular technique, specifying the task implemented and the granularity of the model.

\subsection{Fuzzy Logic}

Fuzzy Logic (FL) defines a framework in which the inherent ambiguity of real information can be captured, modeled and used to reason with uncertainty. An introduction to FL can be found in [17] and [40]. FL is not a machine learning technique, nevertheless due to its ability to handle uncertainty it is used in combination with other machine learning techniques in order to produce behavior models that are able to capture and to manage the uncertainty of human behavior. A traditional fuzzy logic inference system is divided into three steps: (1) fuzzification; (2) fuzzy inference; and (3) defuzzification. FL in UM does not necessarily realize these three steps, but a subset of them. Typically FL has been used to implement applications that are based on a recommendation task. In these applications FL provides the ability of mixing different user preferences and profiles that are satisfied to a certain degree. FL has been used to implement recommendation tasks [27], where fuzzy inference is used for recommendation purposes using user profiles obtained with hierarchical unsupervised 
clustering. In [1] fuzzy logic was used to model user behavior and give recommendation using this fuzzy behavior model. Although there is not strictly a fuzzy inference process, the stereotypes that characterize users are modeled using membership functions, and the recommendation process is done using a fuzzy AND operator. [32] presents a system designed to recommend products in an e-commerce site, according to how well this product satisfies user preferences. The score of an item (according to how much that item matches user interests) is done using an OWA (Ordered Weighted Averaging) operator. This family of operators allows the representation of fuzzy logic connectives and the aggregation of different user preferences.

FL has been used for filtering [38]. In this case FL provides a soft filtering process based on the degree of concordance between user preferences and the elements being filtered.

Table 1 summarizes relevant studies and applications of FL for UM. The columns detail the application, the data, the results obtained, the type of task (T) for which the $\mathrm{SC}$ technique was used and $(\mathrm{I} / \mathrm{G})$ if the system created a model for each individual (I) or for groups of users $(\mathrm{G})$.

Table 1. Characteristics of some Fuzzy Logic- based User Modeling applications.

\begin{tabular}{|c|c|c|c|c|c|}
\hline & Application & Data & Outcome & $\mathrm{T}$ & $\mathrm{I} / \mathrm{G}$ \\
\hline $\begin{array}{l}{[27]} \\
\text { Nasraoui } \\
\text { and Petenes } \\
(2003)\end{array}$ & $\begin{array}{l}\text { Web recommendation } \\
\text { system based on a } \\
\text { fuzzy inference engine } \\
\text { that uses a rule-based } \\
\text { representation of the } \\
\text { user profile. }\end{array}$ & $\begin{array}{l}12 \text { days access log data of the } \\
\text { Web site of the Dep. Comp. } \\
\text { Eng. at the University of } \\
\text { Missouri. }\end{array}$ & $\begin{array}{l}\text { Fuzzy } \\
\text { recommendation } \\
\text { achieves high } \\
\text { coverage compared } \\
\text { to other machine } \\
\text { learning solutions. }\end{array}$ & $\mathrm{R}$ & G \\
\hline $\begin{array}{l}{[38]} \\
\text { Vrettos and } \\
\text { Stafylopati } \\
(2001)\end{array}$ & $\begin{array}{l}\text { Agent for information } \\
\text { retrieval and filtering in } \\
\text { the context of e- } \\
\text { learning. }\end{array}$ & $\begin{array}{l}\text { Cranfield data set } \\
\text { (www.cs.utk.edu/lsi) which } \\
\text { includes } 1398 \text { documents, } 225 \\
\text { queries and an average of } 8.2 \\
\text { relevant documents per query. }\end{array}$ & $\begin{array}{l}\text { Re-ranking the } \\
\text { search according to } \\
\text { user's profile. }\end{array}$ & $\mathrm{F}$ & I \\
\hline $\begin{array}{l}{[1]} \\
\text { Ardissono } \\
\text { and Goy } \\
(1997)\end{array}$ & $\begin{array}{l}\text { Introduction of } \\
\text { personalization } \\
\text { techniques in a shell } \\
\text { supporting the } \\
\text { construction of } \\
\text { adaptive web stores. }\end{array}$ & Not Presented. & $\begin{array}{l}\text { FL can be applied } \\
\text { in electronic sales } \\
\text { to produce } \\
\text { personalized } \\
\text { environments. }\end{array}$ & $\mathrm{R}$ & I \\
\hline $\begin{array}{l}{[32]} \\
\text { Schmitt et } \\
\text { al. (2003) }\end{array}$ & $\begin{array}{l}\text { Recommendation of } \\
\text { items of an e-commerce } \\
\text { site to its users using a } \\
\text { structure-based system. }\end{array}$ & $\begin{array}{l}\text { Preferences specified by the } \\
\text { user. }\end{array}$ & $\begin{array}{l}\text { On-line demo: } \\
\text { www2.dfki.de:808 } \\
0 \\
\text { /mautmachine/html }\end{array}$ & $\mathrm{R}$ & I \\
\hline
\end{tabular}

\subsection{Neural Networks}

A Neural Network (NN) is an information processing paradigm that is inspired by the way biological nervous systems, such as the brain, process information. Comprehensive introductions to Neural Networks can be found in [8] and [12]. Neural networks, with their remarkable ability to derive meaning from complicated or imprecise data, can be used to extract complex patterns. A trained neural network can be thought of as an expert in the category of information it has been given to analyse.

NNs is a powerful method to model human behaviour Traditionally, NNs have been used for classification and recommendation in order to group together users with the same characteristics and create profiles. Some examples are in [5], which uses NN 
to classify user navigation paths, and [11], which uses Self Organizing Maps (SOM), an unsupervised $\mathrm{NN}$ that transforms highly dimensional data into a two dimensional grid, to classify documents based on a subjectively predefined set of clusters in a specific domain. NNs have also been used for recommendation in [31], which predicts the next step for a given user trajectory in a virtual environment, and in [2][3] which models student behavior for an intelligent tutoring system. NNs have also been used for filtering and prediction in [34] and [33] respectively. Table 2 summarizes some applications of Neural Networks for UM.

Table 2. Characteristics of some Neural Networks- based User Modeling applications.

\begin{tabular}{|c|c|c|c|c|c|}
\hline & Application & Training Data & Outcome & $\mathrm{T}$ & $\mathrm{I} / \mathrm{G}$ \\
\hline $\begin{array}{l}{[5]} \\
\text { Bidel et al. } \\
\text { (2003) }\end{array}$ & $\begin{array}{l}\text { Classification and } \\
\text { tracking of user } \\
\text { navigation. }\end{array}$ & $\begin{array}{l}\text { Data generated from an } \\
\text { on-line encyclopedia. }\end{array}$ & $\begin{array}{l}\text { A labelled approach to } \\
\text { the problem produces } \\
\text { better accuracy. }\end{array}$ & $\mathrm{C}$ & G \\
\hline $\begin{array}{l}{[31]} \\
\text { Sas et al. } \\
(2003)\end{array}$ & $\begin{array}{l}\text { Prediction of user's next } \\
\text { step in a virtual } \\
\text { environment }\end{array}$ & $\begin{array}{l}30 \text { users performed } \\
\text { exploration and } \\
\text { searching within the } \\
\text { environment. }\end{array}$ & $\begin{array}{l}\text { Very accurate } \\
\text { predictions of the next } \\
\text { step }\end{array}$ & $\mathrm{R}$ & $\mathrm{G}$ \\
\hline $\begin{array}{l}{[34]} \\
\text { Shepperd } \\
\text { (2002) }\end{array}$ & $\begin{array}{l}\text { Adaptive filtering } \\
\text { system for electronic } \\
\text { news using stereotypes. }\end{array}$ & $\begin{array}{l}\text { The Halifax Herald } \\
\text { Ltd. }\end{array}$ & $\begin{array}{l}\text { Very useful for readers } \\
\text { with specific } \\
\text { information needs. }\end{array}$ & $\mathrm{F}$ & I \\
\hline $\begin{array}{l}{[2][3]} \\
\text { Beck and } \\
\text { Woolf. } \\
(1998)\end{array}$ & $\begin{array}{l}\text { Construction of a } \\
\text { student model for an } \\
\text { intelligent tutoring } \\
\text { system. }\end{array}$ & $\begin{array}{l}\text { Data collected by the } \\
\text { tutoring system }\end{array}$ & $\begin{array}{l}\text { NN-based } \\
\text { recommendation to } \\
\text { each individual. }\end{array}$ & $\mathrm{R}$ & G \\
\hline $\begin{array}{l}{[33]} \\
\text { Shavlik and } \\
\text { Eliassi } \\
(2001)\end{array}$ & $\begin{array}{l}\text { Adaptive agents that } \\
\text { retrieve and extract } \\
\text { information by accepting } \\
\text { user preferences in the } \\
\text { form of instructions. }\end{array}$ & $\begin{array}{l}\text { Instructions given } \\
\text { directly by the user and } \\
\text { user rated web pages. }\end{array}$ & $\begin{array}{l}\text { Faciliates creating } \\
\text { intelligent agents } \\
\text { combining user } \\
\text { instructions with } \\
\text { machine learning. }\end{array}$ & $\mathrm{F} / \mathrm{P}$ & I \\
\hline
\end{tabular}

\subsection{Genetic Algorithms}

Genetic Algorithms (GAs) are search algorithms based on the mechanics of natural selection [10]. A GA begins with a set of solutions (chromosomes) called the population. Solutions from one population are taken and used to form a new population, which are closer to the optimum solution to the problem at hand. GAs are a search strategy that is tailored for vast, complex, multimodal search spaces.

Table 3. Characteristics of some Genetic- based User Modeling applications.

\begin{tabular}{|l|l|l|l|c|c|}
\hline & \multicolumn{1}{|c|}{ Application } & \multicolumn{1}{|c|}{ Input Data } & \multicolumn{1}{c|}{ Outcome } & $\mathrm{T}$ & $\mathrm{I} / \mathrm{G}$ \\
\hline $\begin{array}{l}{[23]} \\
\text { Min et al. } \\
(2001)\end{array}$ & $\begin{array}{l}\text { Profiling behavior of e- } \\
\text { commerce customers. }\end{array}$ & $\begin{array}{l}\text { Set of questions } \\
\text { regarding size of } \\
\text { company, e-purchasing } \\
\text { usage, etc. }\end{array}$ & $\begin{array}{l}\text { GA are useful for the } \\
\text { discovery of profiles } \\
\text { of e-commerce } \\
\text { customers. }\end{array}$ & $\mathrm{R}$ & $\mathrm{G}$ \\
\hline $\begin{array}{l}{[30]} \\
\text { Romero et } \\
\text { al. (2003) }\end{array}$ & $\begin{array}{l}\text { Discovering prediction } \\
\text { rules from student } \\
\text { usage information to } \\
\text { improve web courses. }\end{array}$ & $\begin{array}{l}\text { Stored information of a } \\
\text { Linux course } \\
\text { developed with AHA!. }\end{array}$ & $\begin{array}{l}\text { The rules produced } \\
\text { are better that } \\
\text { traditional rule } \\
\text { extraction algorithms. }\end{array}$ & $\mathrm{R}$ & $\mathrm{G}$ \\
\hline $\begin{array}{l}{[7]} \\
\text { Fan et al. } \\
(2000)\end{array}$ & $\begin{array}{l}\text { Personalization of } \\
\text { search engines using } \\
\text { automatic term weight- } \\
\text { ing }\end{array}$ & $\begin{array}{l}\text { Cranfield text } \\
\text { Collection and Federal } \\
\text { Register (FR) text } \\
\text { collection. }\end{array}$ & $\begin{array}{l}\text { GA Automatic } \\
\text { weighting improves } \\
\text { the retrieval } \\
\text { performance quite } \\
\text { dramatically. }\end{array}$ & $\mathrm{F}$ & $\mathrm{G}$ \\
\hline
\end{tabular}


In general GAs have been used for Recommendation in the form of rules, which can capture user goals and preferences, because they perform a global search and cope better with attribute interaction than algorithms used in data mining, where the search is more local. Examples of this approach are [30] for student modeling and [23] for profiling of e-commerce customers. Nevertheless, they have also been applied for filtering [7]. Table 3 summarizes relevant applications of GAs for UM.

\subsection{Fuzzy Clustering}

In non-fuzzy or hard clustering, data is divided into crisp clusters, where each data point belongs to exactly one cluster. In Fuzzy Clustering (FC), the data points can belong to more than one cluster and associated with each data point are membership grades which indicate the degree to which it belongs to the different clusters. One of the key elements of any FC system is the definition of the concept of distance used for the creation of the clusters. The most widely used fuzzy clustering algorithm is the Fuzzy C-Means (FCM) Algorithm [4]. There are other algorithms, which basically are variations of the original FCM, like the Fuzzy c-Medoids Algorithm (FCMdd) or the Fuzzy c-Trimered Medoids Algorithm (FCTMdd) [19].

Table 4. Characteristics of some Fuzzy Clustering- based User Modeling applications.

\begin{tabular}{|l|l|l|l|c|c|}
\hline \multicolumn{1}{|c|}{ Application } & \multicolumn{1}{c|}{ Input Data } & \multicolumn{1}{c|}{ Outcome } & T & I/G \\
\hline $\begin{array}{l}{[20]} \\
\text { Lampinen } \\
\text { and Koivisto } \\
(2002)\end{array}$ & $\begin{array}{l}\text { Obtain application } \\
\text { profiles from network } \\
\text { traffic data to manage } \\
\text { network resources. }\end{array}$ & $\begin{array}{l}\text { 274000 samples of } \\
\text { different } \\
\text { applications from an } \\
\text { edge router of a LAN } \\
\text { network. }\end{array}$ & $\begin{array}{l}\text { FCM produced better results } \\
\text { than SOM. A method for the } \\
\text { comparison of both solu- } \\
\text { tions is also introduced. }\end{array}$ & R & G \\
\hline $\begin{array}{l}{[25]} \\
\text { Nasraoui et } \\
\text { al. (1999) }\end{array}$ & $\begin{array}{l}\text { A new algorithm (CARD) } \\
\text { to mine user profiles from } \\
\text { access logs is proposed. }\end{array}$ & $\begin{array}{l}\text { 12 day log data of } \\
\text { the Dep. of Comp. } \\
\text { Eng.. at Univ. of } \\
\text { Missouri. }\end{array}$ & $\begin{array}{l}\text { CARD is very effective for } \\
\text { clustering many different } \\
\text { profiles in user sessions. }\end{array}$ & R & G \\
\hline $\begin{array}{l}{[16]} \\
\text { Joshi et al. } \\
(2000)\end{array}$ & $\begin{array}{l}\text { Two algorithms to mine } \\
\text { user profiles: FCM dd }\end{array}$ & $\begin{array}{l}\text { CSEE logs of Univ. } \\
\text { of Maryland }\end{array}$ & $\begin{array}{l}\text { Both algorithms extract } \\
\text { interesting user profiles. } \\
\text { FCM is not able to handle } \\
\text { noise as effectively as } \\
\text { FCTM. }\end{array}$ & C & G \\
\hline $\begin{array}{l}{[19]} \\
\text { Krishnapura } \\
\text { et al. (2001) }\end{array}$ & $\begin{array}{l}\text { Web access log analysis } \\
\text { for user profiling using } \\
\text { RFCMdd (Robust Fuzzy }\end{array}$ & $\begin{array}{l}\text { Five days of CSEE } \\
\text { web server activity } \\
\text { of Univ. of } \\
\text { Maryland. }\end{array}$ & $\begin{array}{l}\text { RFCMdd is very effective } \\
\text { for clustering of relational } \\
\text { data. }\end{array}$ & C & G \\
\hline
\end{tabular}

Typically, FC applied to UM has to use techniques that can handle relational data because the information used to create stereotypes (pages visited, characteristics of the user, etc.) cannot be represented by numerical vectors. In these systems the definition of distance is done using vectorial representations of user interactions with the adaptive hypermedia system. FC for UM, by its definition, is used for recommendation and classification tasks. [20], [25] and [26] are examples of applications that implement a recommendation task using FC. Examples of classification tasks are [16] and [19]. Table 4 summarizes some studies and applications of FC for UM. 


\subsection{Neuro-Fuzzy Systems}

Neuro-Fuzzy systems (NFS) use NNs to extract rules and/or membership functions from input-output data to be used in a Fuzzy Inference System. With this approach, the drawbacks of NNs and FL, the black box behavior of NNs and the problems of finding suitable membership values for FL, are avoided. NFS automate the process of transferring expert or domain knowledge into fuzzy rules. [14] and [15] describe with more detail the basic concepts of NFS. One of the most important NFS is ANFIS [13], which has been used in a wide range of applications [6]. NFS are especially suited for applications where user interaction in model design or interpretation is desired.

NFS are basically FL systems with an automatic learning process provided by NN. The combination of NN and fuzzy sets offers a powerful method to model human behavior which allows NFS to be used for a variety of tasks. [21] and [35] use a NFS for Recommendation in an e-commerce site and for an on-line course respectively. [22] uses NFS to implement multi-attribute decision making with the purpose of planning the contents of a web-course according to the knowledge level of the student. [9] use NFS for prediction of a simulated aircraft control. Table 5 summarizes some studies and applications of NFS for UM.

Table 5. Characteristics of some NeuroFuzzy- based User Modeling applications.

\begin{tabular}{|c|c|c|c|c|c|}
\hline & Application & Test bed & Outcome & $\mathrm{T}$ & $\mathrm{I} / \mathrm{G}$ \\
\hline $\begin{array}{l}{[21]} \\
\text { Lee }(2001)\end{array}$ & $\begin{array}{l}\text { Mobile web shopping } \\
\text { agent that finds products } \\
\text { that suit user needs using a } \\
\text { NFS and FL. }\end{array}$ & $\begin{array}{l}\text { A test is } \\
\text { implemented using a } \\
\text { product data-base } \\
\text { with } 200 \text { items and } 8 \\
\text { categories. } \\
\end{array}$ & $\begin{array}{l}\text { Provides a more } \\
\text { efficient result when } \\
\text { compared with other } \\
\text { solutions; processing } \\
\text { time is shorter. }\end{array}$ & $\mathrm{R}$ & I \\
\hline $\begin{array}{l}{[35]} \\
\text { Stathacopoulou } \\
\text { et al. (2003) }\end{array}$ & Student Modeling & $\begin{array}{l}\text { A set of simulated } \\
\text { students. }\end{array}$ & $\begin{array}{l}\text { High accuracy in the } \\
\text { diagnosis of student } \\
\text { problems during } \\
\text { learning. }\end{array}$ & $\mathrm{C} / \mathrm{P}$ & G \\
\hline $\begin{array}{l}{[22]} \\
\text { Magoulas et al. } \\
(2001)\end{array}$ & $\begin{array}{l}\text { Intelligent decision making } \\
\text { for recommending educa- } \\
\text { tional content in a web- } \\
\text { based course depending on } \\
\text { knowledge level }\end{array}$ & $\begin{array}{l}\text { "Introduction to } \\
\text { Computer Science" } \\
\text { course of the Univ. } \\
\text { of Athens. }\end{array}$ & $\begin{array}{l}\text { Successful handling of } \\
\text { fuzziness associated } \\
\text { with the evaluation of } \\
\text { learner's knowledge. }\end{array}$ & $\mathrm{C} / \mathrm{R}$ & G \\
\hline $\begin{array}{l}{[9]} \\
\text { George and } \\
\text { Cardullo (1999) }\end{array}$ & $\begin{array}{l}\text { Modeling of human } \\
\text { behavior. }\end{array}$ & $\begin{array}{l}10 \text { subjects collected } \\
\text { data for the one } \\
\text { dimensional } \\
\text { compensatory task. }\end{array}$ & $\begin{array}{l}\text { Generate a model of } \\
\text { human behavior. }\end{array}$ & $\mathrm{P}$ & G \\
\hline
\end{tabular}

\section{Criteria for the Selection of Techniques}

Maybe seen from the preceding discussion, no SC technique is ideal for all situations. Each one captures different relationships among the data available. In this section we present guidelines to help decide which technique to use when developing an $\mathrm{AH}$ application. Table 6 summarizes the characteristics of the techniques presented along seven dimensions. The first four dimensions capture the main problems that machine learning for user modeling faces according to [39]: Computational Complexity, i.e. off-line processing; Dynamic Modeling, which indicates the suitability of the tech- 
nique to change a user model on-the-fly; Labeled/Unlabeled, which reflects the need of labeled data; and Size of training data, which reflects the amount of data needed to produce a reliable user model. The remaining dimensions present other relevant information: the ability of the techniques to handle uncertainty (Uncertainty), i.e. to produce user model that takes into account the inherent fuzziness of user modeling; the ability to handle noisy data (Noisy Data), i.e. how noisy training data will affect the user model produced; and the interpretability (Interpret.) of the results, i.e. how easy is for a human to understand the knowledge captured.

Table 6. Characteristics of different Soft Computing techniques applied to User Modeling.

\begin{tabular}{|c|c|c|c|c|c|c|c|}
\hline & Complexity & $\begin{array}{c}\text { Dynamic } \\
\text { Modeling }\end{array}$ & $\begin{array}{c}\text { Labeled / } \\
\text { Unlabeled }\end{array}$ & $\begin{array}{c}\text { Size of } \\
\text { Training } \\
\text { Data }\end{array}$ & Uncertainty & $\begin{array}{c}\text { Noisy } \\
\text { Data }\end{array}$ & $\begin{array}{c}\text { Inter- } \\
\text { pret. }\end{array}$ \\
\hline Fuzzy Logic & Med & Yes & N/A & N/A & Yes & Yes & High \\
\hline $\begin{array}{c}\text { Neural } \\
\text { Networks }\end{array}$ & High & Yes & Both & High & Yes & Yes & Low \\
\hline $\begin{array}{c}\text { Genetic } \\
\text { Algorithms }\end{array}$ & High & No & N/A & N/A & No & Yes & Low \\
\hline $\begin{array}{c}\text { Fuzzy } \\
\text { Clustering }\end{array}$ & High/Med & No & Both & Med/High & Yes & Yes & Low \\
\hline Neuro-Fuzzy & High & Yes & Labelled & Med/High & Yes & Yes & $\begin{array}{c}\text { Med/Hi } \\
\text { gh }\end{array}$ \\
\hline
\end{tabular}

For example, NNs have a high training complexity, although they can have a realtime response time. NFS have a High/Medium interpretability, which depends on the architecture of the system, for example ANFIS produce systems with high interpretability. Traditional GAs are not able to cope with dynamic modeling problems, nevertheless some recent approaches present dynamic modeling using evolutionary computation for specific problems [36]. Two are the main criteria that determine the soft computing technique that is going to be used by a specific adaptive application: (1) the type of task and (2) the interpretability needed for the results. As was previously discussed the main types of task are: Prediction; Recommendation; Classification; and Filtering. There are two possible values for Interpretability, needed or not relevant. The first one expresses the necessity of having a human understandable output while the second one states that this factor is not important. Table 7 presents guidelines related to what soft computing techniques are useful considering the criteria previously introduced. The techniques are classified according to the set of references used in this study. This does not necessarily mean that the techniques cannot be used to implement other types of tasks. For example, NNs are basically used for task that need no interpretability. Nevertheless some recent approaches describe techniques to extract the knowledge embedded in NN [37]. The combination of Tables 6 and 7 can be used to guide a choice of which technique to use for user modeling in an AH system. First, Table 7 can be used to identify the set of techniques suitable for the adaptive application and, after that, Table 6 can be used to refine the search and take the final decision. 
Table 7. Techniques recommended for each combination of the decision variables.

\begin{tabular}{|l|l|l|}
\hline \multicolumn{1}{|c|}{ Task } & \multicolumn{2}{c|}{ Interpretability } \\
\cline { 2 - 3 } Prediction & Needed & \multicolumn{1}{c|}{ Not Needed } \\
\hline Recommendation & $\begin{array}{l}\text { NeuroFuzzy } \\
\text { Fuzzy Logic }\end{array}$ & $\begin{array}{l}\text { Neural networks } \\
\text { Genetic Algorithms } \\
\text { Fuzzy Clustering }\end{array}$ \\
\hline Classification & Neuro Fuzzy & $\begin{array}{l}\text { Neural Networks } \\
\text { Fuzzy Clustering }\end{array}$ \\
\hline Filtering & Fuzzy Logic & $\begin{array}{l}\text { Neural Networks } \\
\text { Genetic Algorithms }\end{array}$ \\
\hline
\end{tabular}

\section{Conclusions}

This paper has presented a brief review of the state of the art of SC techniques use within the area of adaptive hypermedia systems. The review demonstrates that one of the main problems that the development of AH faces is the lack of any kind of standardization for the design of user models. In order to improve this situation this paper has tried to give a set of guidelines that formalize the design of user models using a SC approach. It is our opinion that the future of User Modeling is in hybrid systems. As has been shown, each technique captures different elements of user behavior. The combination of these SC techniques among themselves and with other machine learning techniques, will provide a useful framework to efficiently capture the natural complexity of human behavior.

\section{Acknowledgments}

The work presented in this paper is funded by the UK Arts and Humanities Research Board (AHRB grant reference: MRG/AN9183/APN16300).

\section{References}

1. Ardissono, L., Goy, A.:Tailoring the Interaction with Users in Electronic Shops, Proceedings of the $7^{\text {th }}$ International Conference on User Modeling, UM97, Banff, Canada, 1997

2. Beck, J., Jia, P., Sison, J., Mostow, J.: Predicting Student Help-Request Behavior in an Intelligent Tutor for Reading, Proc. of the $9^{\text {th }}$ Int. Conf. on User Modeling, LNAI 2702, pp. 303-312, 2003

3. Beck, J.E., Woolf, B.P.: Using a Learning Agent with a Student Model, LNCS 1452, 1998

4. Bezdek, J.C.: Pattern Recognition with Fuzzy Objective Function Algorithms, Plenum Press, 1981

5. Bidel, S, Lemoine, L., Piat, F.: Statistical machine learning for tracking hypermedia user behavior, $2^{\text {nd }}$ Workshop on Machine Learning, Information Retrieval and User Modeling, $9^{\text {th }}$ Int. Conf. in UM, 2003

6. Bonissone,P., Badami, C., Chiang, X.: Industrial Applications of Fuzzy Logic at General Electric, Proceedings of the IEEE, 83(3), pp. 450-465, 1995

7. Fan, W., Gordon, M. D., Pathak, P.: Personalization of Search Engine Services for Effective Retrieval and Knowledge management. In Proc. Of the $21^{\text {st }}$ Int. Conf. on Information Systems, pp. 20-34, 2000

8. Fausett L., Fundamentals of Neural Networks, Prentice-Hall, 1994

9. George G., Cardullo, F.: Application of Neuro-Fuzzy Systems to Behavioral Representation in Computer Generated Forces, Proc. $8^{\text {th }}$ Conf. on Comp. Generated Forces, pp. 575-585, 1999

10. Goldberg, D.: Genetic Algorithms in Search, Optimization, and Machine Learning. Addison-Wesley, 1989

11. Goren-Bar, D., Kuflik, T., Lev, D., Shoval, P.: Automatic Personal Categorization Using Artificial Neural Networks, $8^{\text {th }}$ International Conference on User Modeling 2001, LNAI 2109, pp. 188-198, 2001 
12. Haykin S., Neural Networks, 2nd Edition, Prentice Hall, 1999

13. Jang, J.S.: ANFIS: Adaptive-Network-Based Fuzzy Inference Systems, IEEE Transactions on Systems, Man, and Cybernetics, Vol. 23(3), pp. 665-685, May 1993.

14. Jang, J.S.R., Sun, C.T.: Neurofuzzy modelling and control,in Proceedings IEEE, 1995

15. Jang, J.S.R., Sun, C.T:Neurofuzzy and Soft Computing, Prentice Hal, 1997

16. Joshi, A., Joshi, K., Krishnapuram, R., On mining Web Access Logs, in Proceedings of the ACMSIGMOD Workshop on Research Issues in Data Mining and Knowledge Discovery, pp. 63-69, 2000

17. Klir, J., Yuan,B.: Fuzzy Sets and Fuzzy Logic. Theory and Applications, Prentice Hall, 1995

18. Kobsa, A.: Generic User Modeling Systems, User Modeling and User-Adapted Interaction 11, 49-63, 2001

19. Krishnapuram, R., Joshi, A., Nasraoui, O., Yi, L., Low-Complexity Fuzzy Relational Clustering Algorithms for Web Mining, in IEEE Transactions on Fuzzy Systems, Vol. 9 (4), pp. 595-608, 2001

20. Lampinen, T., Koivisto, H.: Profiling Network Applications with Fuzzy C-Means Clustering and SelfOrganising Map, Int. Conf. on Fuzzy Systems and Knowledge Discovery, 2002

21. Lee, R.S.T.:iJADE IWShopper: A New Age of Intelligent Web Shopping System Based on FuzzyNeuro Agent Technology. In Web Intelligence: Research and Development, LNAI 2198, pp. 403-412, 2002

22. Magoulas, G.D., Papanikolau, K.A., Grigoriadou, M.: Neuro-fuzzy synergism for planning the content in a web-based course, Informatica Vol. 25(1), 2001

23. Min, H., Smolinski, T., Boratyn, G.: A GA-based Data Mining Approach to Profiling the Adopters of Epurchasing, Proc. of the 3rd Int. Conf. on Information Reuse and Integration, pp. 1-6, 2001

24. Nasraoui, O., Cardona, C., Rojas, C., Gonzalez, F.: Mining Evolving User Profiles in Noisy Web Clickstream Data with a Scalable Immune System Clustering Algorithm. In Workshop Notes of WEBKDD 2003: Web Mining as Premise to Effective\&Intelligent Web Applications, pp. 71-81, 2003

25. Nasraoui, O., Frigui, H., Joshi, A., Krishnapuram, R.: Mining Web Access Logs Using Relational Competitive Fuzzy Clustering, $8^{\text {th }}$ Intl. Fuzzy Systems Association World Congress - IFSA 99, 1999

26. Nasraoui, O., Krishnapuram, R.: Extracting Web User Profiles Using Relational Competitive Fuzzy Clustering. In International Journal on Artificial Intelligence Tools, Vol. 9(4), pp. 509-526, 2000

27. Nasraoui, O., Petenes, C.: Combining Web Usage Mining and Fuzzy Inference for Website Personalization. In WEBKDD 2003: Web Mining as Premise to Effective Web Applications, pp. 37-46, 2003

28. Pal, S.K., Talwar, V., Mitra, P.: Web Mining in Soft Computing Framework: Relevance, State of the Art and Future Directions, IEEE Transactions on Neural Networks, Vol. 13(5), pp.1163 - 1177, 2002

29. Perkowitz, M., Etzioni, O.: Adaptive Web Sites. Communications of the ACM, Vol. 43(8), 152-158, 2000

30. Romero, C., Ventura, S., de Bra, P.: Discovering Prediction Rules in AHA! Courses, Proceedings of the $9^{\text {th }}$ International Conference on User Modeling, LNAI 2702, pp. 25-34, 2003

31. Sas, C., Reilly, R., O’Hare, G.: A Connectionist Model of Spatial Knowledge Acquisition in a Virtual Environment. In $2^{\text {nd }}$ Workshop on Machine Learning, Information Retrieval and User Modeling, 2003

32. Schmitt, C., Dengler, D., Bauer, M.: Multivariate Preference Models and Decision Making with the MAUT Machine, in Proc. of the $9^{\text {th }}$ Int. Conf. on User Modeling, LNAI 2702, pp. 297-302, 2003

33. Shavlik, J., Eliassi, T.: A System for building intelligent Agents that Learn to retrieve and Extract Information. In International Journal on User Modeling and User Adapted Interaction, 2001.

34. Sheperd, A., Watters, C., Marath, A.T.: Adaptive User Modeling for Filtering Electronic News. In Proc. of the 35th Annual Hawaii Intl. Conf. on System Sciences (HICSS-02), Vol. 4, 2002

35. Stathacopoulou, R., Grigoriadou, M., Magoulas, G.D.: A Neuro-fuzzy Approach in Student Modeling, Proceedings of the $9^{\text {th }}$ Int. Conf. on User Modeling, UM2003, LNAI 2702, pp. 337-342, 2003

36. Sternberg, M., Reynolds, R.G.: Using cultural algorithms to support re-engineering of rule-based expert systems in dynamic performance environments: a case study in fraud detection Sternberg, IEEE Transactions on Evolutionary Computation ,Vol. 1(4), pp. 225-243, 1997

37. Ticlek, A.B., Andrews, R., Golea, M., Diederich, J.: The truth will come to light: directions and challenges in extracting the knowledge embedded within trained artificial neural networks IEEE Trans. on Neural Networks, Vol. 9(6), pp. 1057-1068, 1998

38. Vrettos, S., Stafylopatis, A.: A Fuzzy Rule-Based Agent for Web Retrieval-Filtering. In Web Intelligence: Research and Development, LNAI 2198, pp. 448-453, 2002

39. Webb, G.I., Pazzani, M.J., Billsus, D.: Machine Learning for User Modeling. In User Modeling an User-Adapted Interaction, (11), pp. 19-29, 2001

40. Yan, J., Ryan, M., Power, J.: Using Fuzzy Logic, Prentice Hall, 1994 